\title{
Vertical velocity and turbulence aspects during Mistral events as observed by UHF wind profilers
}

\author{
J.-L. Caccia ${ }^{1}$, V. Guénard ${ }^{1}$, B. Benech ${ }^{2}$, B. Campistron ${ }^{2}$, and P. Drobinski ${ }^{3}$ \\ ${ }^{1}$ LSEET, CNRS/Université de Toulon, BP132, 83957 La Garde, France \\ ${ }^{2}$ CRA/LA, CNRS/Obs. Midi-Pyrénées, 65300 Campistrous, France \\ ${ }^{3}$ IPSL/SA, CNRS/Université de Paris VI, Jussieu, 75252 Paris Cedex 05, France
}

Received: 1 December 2003 - Revised: 26 April 2004 - Accepted: 12 May 2004 - Published: 29 November 2004

Part of Special Issue "10th International Workshop on Technical and Scientific Aspects of MST Radar (MST10)"

\begin{abstract}
The general purpose of this paper is to experimentally study mesoscale dynamical aspects of the Mistral in the coastal area located at the exit of the Rhônevalley. The Mistral is a northerly low-level flow blowing in southern France along the Rhône-valley axis, located between the French Alps and the Massif Central, towards the Mediterranean Sea. The experimental data are obtained by UHF wind profilers deployed during two major field campaigns, MAP (Mesoscale Alpine Program) in autumn 1999, and ESCOMPTE (Expérience sur Site pour COntraindre les Modèles de Pollution atmosphériques et de Transports

teristics. In addition, those vertical motions are found to be much less developed during the nighttimes because of the stabilization of the nocturnal planetary boundary layer due to a ground cooling. The enhanced turbulent dissipation-rate values found at lower levels during the afternoons of weak Mistral cases are consistent with the installation of the summer convective boundary layer and show that, as expected in weaker Mistral events, the convection is the preponderant factor for the turbulence generation. On the other hand, for stronger cases, such a convective boundary layer installation is perturbed by the Mistral.
\end{abstract} d'Emission) in summer 2001.

Thanks to the use of the time evolution of the vertical profile of the horizontal wind vector, recent works have shown that the dynamics of the Mistral is highly dependent on the season because of the occurrence of specific synoptic patterns. In addition, during summer, thermal forcing leads to a combination of sea breeze with Mistral and weaker Mistral due to the enhanced friction while, during autumn, absence of convective turbulence leads to substantial acceleration as low-level jets are generated in the stably stratified planetary boundary layer. At the exit of the Rhône valley, the gap flow dynamics dominates, whereas at the lee of the Alps, the dynamics is driven by the relative contribution of "flow around" and "flow over" mechanisms, upstream of the Alps. This paper analyses vertical velocity and turbulence, i.e. turbulent dissipation rate, with data obtained by the same UHF wind profilers during the same Mistral events.

In autumn, the motions are found to be globally and significantly subsident, which is coherent for a dry, cold and stable flow approaching the sea, and the turbulence is found to be of pure dynamical origin (wind shears and mountain/lee wave breaking), which is coherent with non-convective situations.

In summer, due to the ground heating and to the interactions with thermal circulation, the vertical motions are less pronounced and no longer have systematic subsident chara-

Correspondence to: J.-L. Caccia

(caccia@1seet.univ-tln.fr)
Key words. Meteorology and atmospheric dynamics (Mesoscale meteorology, turbulence) - Radio science (Instruments and techniques)

\section{Introduction}

The Mistral is a northerly low-level, orography-induced, cold-air out-break over the Gulf of Lions, blowing off the shore of the south-eastern region of France at any season. The climate of this area is under the influence of the Mistral which brings clear sky. It is frequently observed to extend as far as a few hundreds of kilometers offshore and is one of the primary causes of storms over the northwestern Mediterranean.

On meeting the Alpine range, a westerly to northerly synoptic flow is deflected westward by the Coriolis force, as well as the pressure build up on the upstream edge of the range. As the flow experiences channelling in the Rhône valley separating the French Alps, to the east, from the Massif Central, to the west, by a gap of $200 \mathrm{~km}$ long and $40 \mathrm{~km}$ width (see Figs. 1 and 2), it is substantially accelerated, giving birth to the Mistral (Pettré, 1982).

Although some of the large-scale features of the Mistral are well understood, thus well forecasted, the mesoscale aspects, such as the temporal, vertical and horizontal variabilities, the exact onset and cessation times have still to be in- 
(a) 06 Nov 19991200 UTC

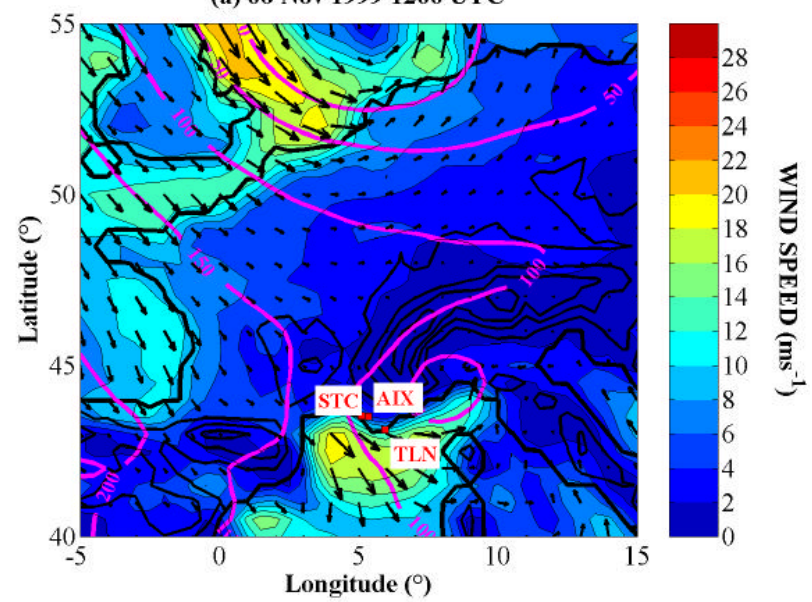

(b) 07 Nov 19991200 UTC

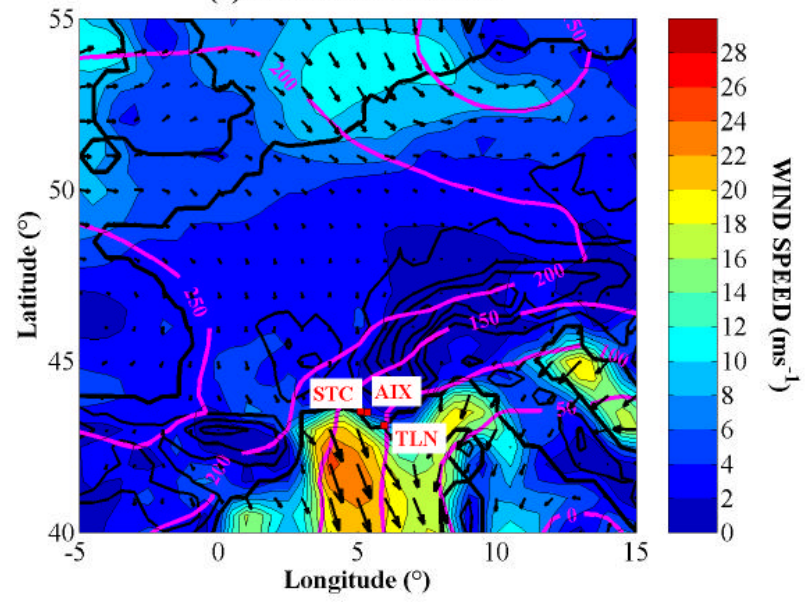

Fig. 1. Map of surface wind and geopotential at $1000 \mathrm{hPa}$ above western Europe in a typical Mistral situation from ECMWF-model analyses. The autumn case (see the text) is presented : (a) 6 November 1999, 12:00 UTC and (b) 7 November 1999, 12:00 UTC. The wind speed is indicated in color code and the direction by arrows. The thick and narrow lines show the shore lines and the topography levels every $500 \mathrm{~m}$, respectively, used by the model.

vestigated. During MAP (Mesoscale Alpine Program, autumn 1999, see Bougeault et al., 2001) and ESCOMPTE (Expérience sur Site pour COntraindre les Modèles de Pollution atmosphériques et de Transport d'Emissions, summer 2001, see Cros et al., 2004) field experiments, an UHF-wind profiler network has been deployed in the coastal region of south-eastern France to document the spatial and temporal structure of the tropospheric flow and in particular during some Mistral events. Guénard et al. (2002) reported preliminary results from UHF-profiler data during several Mistral events, and Drobinski et al. (2003) reported combined and complementary observations of the wind field made by airborne Doppler Lidar (WIND) and UHF-wind profilers in a Mistral situation. The networking approach, combined with the high vertical $(75 \mathrm{~m})$ and time $(5 \mathrm{~min})$ resolutions of the UHF-wind profilers, enables the study of the mesoscale inhomogeneity and unsteadiness aspects of the Mistral, as well as

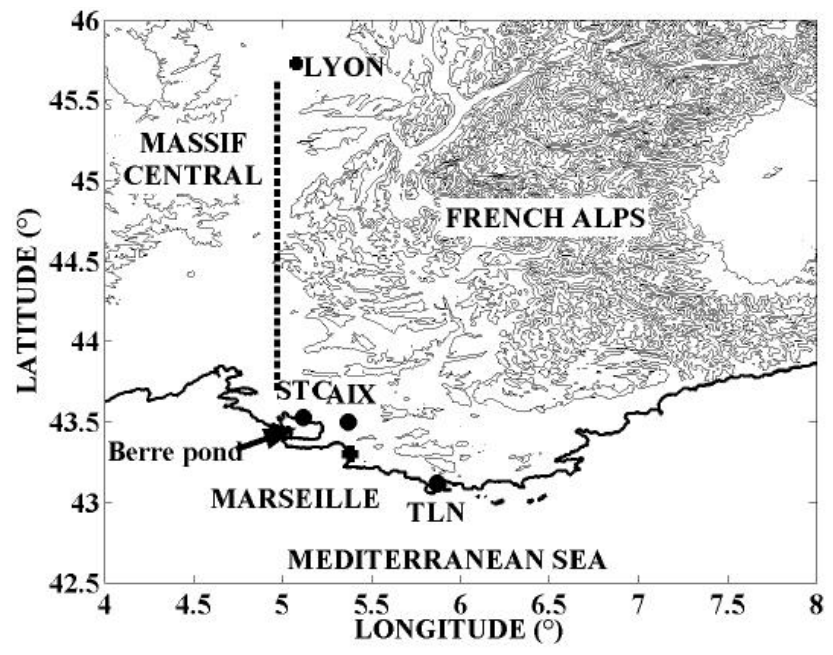

Fig. 2. Area in southern France targeted by our Mistral study. The UHF wind profiler sites, St-Chamas (STC), Aix-les-Milles (AIX) and Toulon (TLN), are indicated. The lower contour line, for the mountainous areas, is at $500 \mathrm{~m}$ of altitude. The dotted line schematically indicates the Rhône-valley axis. The distances between STC and AIX, and between STC and TLN, are $25 \mathrm{~km}$ and $90 \mathrm{~km}$, respectively.

its interactions with the ABL (Atmospheric Boundary Layer) and thermal circulations mainly due to the proximity of the sea.

In this paper, we have chosen to present and analyse wind and turbulence data obtained by two UHF-wind profilers during three Mistral cases (a strong autumn case and a moderate and a weak summer case) among the seven cases that occurred during MAP (three cases) and ESCOMPTE (four cases). In addition to earlier papers on mesoscale modelling aspects related to the Mistral (e.g. Blondin and Bret, 1986), a recent one (Caccia et al., 2001) has shown, for the first time, direct comparisons between time-height diagrams of wind fields directly obtained by UHF-profilers and simulated by the Meso-NH (mesoscale non-hydrostatic) model (Lafore et al., 1998), run over a 10-km resolution domain nested in a 50-km resolution domain. These comparisons have been made during the strong autumn case. The Mistral onset phase is correctly reproduced by meso-NH but the temporal variation of the wind vertical structure is not and the event duration is strongly overestimated. These discrepancies illustrate the difficulty for mesoscale models to correctly describe the ABL dynamics when the topography is very variable (here valleys, mountains, hills and land-to-sea transition) and plays a very important role. In summer, an encreased difficulty is expected due to the thermal forcings (convection and land/sea-breezes).

In addition to those numerical model aspects, very recent experimental work on some of those Mistral events, for different purposes have been made. Drobinski et al. (2003) investigated some 3-D aspects of the wind field obtained during several legs of WIND. Druilhet et al. (2002) stud- 
Table 1. Characteristics of the three Mistral events reported in the present study.

\begin{tabular}{llccccc}
\hline \multirow{2}{*}{ Field Campaign } & \multirow{2}{*}{ Period } & \multirow{2}{*}{ Duration $(\mathrm{h})$} & \multicolumn{2}{c}{ Marignane maximum surface wind } & \multicolumn{2}{c}{ Toulon maximum surface wind } \\
Speed $(\mathrm{m} / \mathrm{s})$ & Direction $\left(^{\circ}\right)$ & Speed (m/s) & Direction $\left({ }^{\circ}\right)$ \\
\hline MAP & & 6-8 November 1999 & 43 & 20 & 350 & 16 \\
ESCOMPTE & 21-23 June 2001 & 72 & 8 & 340 & 12 & 310 \\
ESCOMPTE & 30 June-1 July 2001 & 30 & 14 & 340 & 10 & 270 \\
\hline
\end{tabular}

ied Mistral-induced wind and temperature fluctuations using in-situ aircraft measurements made along legs above the Mediterranean Sea, Jiang et al. (2003) interpreted mesoscale model simulations with satellite images and in-situ, airborne Lidar, airborne Radar and dropsonde data obtained from two aircraft, and Corsmeier et al. (2004) studied the influence of the Mistral on pollutant transport using numerical model simulations and measurements from airborne and groundbased platforms. In a previous work (Guénard et al., 2004), horizontal wind data were already used to show and interpret the sharp time variation of the Mistral vertical structure, to describe the role of the upstream orography, in the autumn case, one radar being installed near the Rhône-valley exit and the second one in the lee of the Alps, and to analyse the interactions between the Mistral and thermal circulations, such as land/sea breezes, in the summer cases. The purpose of the present paper is to extend those results to the analysis and interpretation of the vertical velocity and turbulence data. Such a scientific purpose is motivated by 1) instrumental and 2) mesoscale low-tropospheric physics aspects.

1. Though the capability of UHF radars to make horizontal wind measurements is well established (e.g. Ecklund et al., 1988; Gage et al., 1994), the vertical velocity (w) measurement is much more controversial, mainly at lower levels where ground clutter contaminates w estimations and where a quasi-systematic bias of the order of $-10 \mathrm{~cm} \mathrm{~s}^{-1}$ exists (Angevine, 1997; Lothon et al., 2002; Lothon et al., 2003). Also, a turbulent parameter, such as the turbulent dissipation rate used here, is indirectly estimated from UHF Doppler spectral width (Jacoby-Koaly et al., 2002; Heo et al., 2003). Those two kinds of data need to be reported and validated in the largest variety of meteorological situations. The use of general knowledge about Mistral meteorological conditions and the results already obtained in the three Mistral particular cases reported here constitute a good opportunity to test the vertical velocity and turbulence data provided by UHF-radars.

2. Since the air masses brought by the Mistral are relatively cold and dry when reaching the sea, in absence of thermal effects, as in winter and mid-seasons, they are expected to be globally subsident. Such a systematic behaviour is no longer observed in summer because of ground heating and the land/sea breeze which lead to thermal circulations. Those aspects are investigated here thanks to a combination of vertical velocity and turbulence data. In the summer cases, the development of convective turbulence within the ABL can thus be monitored. Turbulent data are also pertinent in the strong autumn case, since turbulence of dynamical origin is expected because of wind shears and possible mountain/lee wave breaking (Fritts et al., 1994; Ralph et al., 1997).

\section{Brief description of the mistral meteorological aspects}

Westerly to northerly upper-level large-scale flow patterns may lead to Mistral events. They must be associated with a Genoa Gulf cyclone in the lee of the Alps (Tafferner and Egger, 1990; Trigo et al., 1999) that results, at ground level, in a north-south negative pressure gradient component allowing the air masses to be channeled and accelerated along the Rhône valley. The Mistral depth observed near the coast depends on the upstream conditions (wind direction, Froude number, inversion layer height) which determine if the flow passes over or is blocked by the mountains along the lateral sides of the valley. In the case of blocked flow, the Mistral comes from the Rhône valley exit only.

Surface winds usually range from 10 to $20 \mathrm{~m} \mathrm{~s}^{-1}$ over land, but situations leading to offshore winds reaching 30$40 \mathrm{~m} \mathrm{~s}^{-1}$ are not seldom. Maximum winds are found between 500 and $1500 \mathrm{~m}$ AGL and range from 20 to $50 \mathrm{~m} \mathrm{~s}^{-1}$. All these values clearly show that the Mistral is a low-level jet which can strongly affect the ABL dynamics. The duration of the Mistral depends on the synoptic configuration, and ranges from one day to one week or even more in extreme cases.

Table 1 reports some characteristics of the three Mistral events studied here. The mentioned maximum surface wind are actually the maximum hourly averaged wind speeds and their corresponding directions recorded during each event at the Marignane airport, near Marseille, and at Toulon (from the Météo-France surface network).

The wind speed values reported in Table 1 give an idea of the intensity of the Mistral events studied here. The data from the Marignane airport are used to classify those events, i.e. the strong case for the 6-8 November 1999 period, the moderate case for the 30 June-1 July 2001 period and the 
Table 2. Summarized information on the UHF wind profilers used in the present study.

\begin{tabular}{lllcccc}
\hline Field Campaign & Institute Name & Installation Site & Acronyms & Long. $\left(^{\circ}\right)$ & Lat. $\left(^{\circ}\right)$ & $\Delta z(\mathrm{~m})$ \\
\hline MAP/ESCOMPTE & EDF and LA/OMP & St-Chamas & STC & $5.12 \mathrm{E}$ & $43.53 \mathrm{~N}$ & 75 \\
MAP & LSEET and Degréane & Toulon & TLN & $5.97 \mathrm{E}$ & $43.12 \mathrm{~N}$ & 150 \\
ESCOMPTE & LSEET and Degréane & Aix-les-Milles & AIX & $5.37 \mathrm{E}$ & $43.50 \mathrm{~N}$ & 150 \\
\hline
\end{tabular}

weak case for the 21-23 June 2001 period. The surface wind direction values show a classical Mistral characteristics, that is the flow is quasi-southward at Marignane (not far from the Rhône-valley exit) and is more eastward at Toulon. Indeed, after the Rhône-valley exit, the air masses progressively veer eastward around the Genoa cyclone center.

Figure 1 shows two surface maps of the horizontal wind and of the geopotential height at $1000 \mathrm{hPa}$ from the ECMWF (European Center for Medium-range Weather Forecast) model analyses obtained during the strong Mistral case, i.e. 6 November, 12:00 UTC (beginning of the event, Fig. 1a and 7 November, 12:00 UTC (end of the event, Fig. 1b. The role played by the major mountain ranges (Massif Central and Alps) for this N-NW synoptic flow situation over western Europe is clearly visible both from the wind distribution and from the occurrence of the Genoa Gulf cyclone observed downstream the Alps. The installation sites of the UHF profilers used here are indicated on Fig. 1 by the red thick dots near STC, AIX and TLN (see Sect. 3). It is clear that those locations are all under the influence of the Mistral.

\section{Experimental setup}

The measurements, from Degréane UHF-wind profilers (1238 MHz-frequency and $4 \mathrm{~kW}$-peak power), consist of the time evolution of the vertical profiles of the three wind components thanks to one vertical beam and two, or four (depending upon the radar) oblique beams slanted at an offzenith angle of $17^{\circ}$, with the half power beamwidth being $8.5^{\circ}$. Return echoes are due to the air refractive index fluctuations advected by the wind. The wind velocity is estimated from the frequency corresponding to the mean Doppler shift obtained in the radar echo. The turbulent variable used here is the dissipation rate of turbulent kinetic energy $\varepsilon$ deduced from the Doppler spectral width. The details of this radar $\varepsilon$ retrieval technique and its assessment against aircraft data are presented in Jacoby-Koaly et al. (2002).

Data quality control and processing are carried out through a consensus algorithm based on time and height continuity of measured spectra to remove contamination from precipitation, birds, radio frequency interference and others sources. The consensus works over a 30-min period, providing a wind profile each $15 \mathrm{~min}$ from a height of $375 \mathrm{~m}$ up to 2500 $4000 \mathrm{~m}$ AGL (mainly depending upon humidity and turbulence conditions). The vertical resolution and range gate $\Delta z$ is $75 \mathrm{~m}$ or $150 \mathrm{~m}$ (see Table 2).
The Data from two radars are used in our study. During MAP, they were installed at St-Chamas (STC), upstream from the Berre pond near Marseille, and at Toulon (TLN), $90 \mathrm{~km}$ to the east, and during ESCOMPTE, the STC radar was also used, whereas the other radar moved to Aix-lesMilles (AIX), $25 \mathrm{~km}$ to the east (see Fig. 2). Table 2 summarizes this information.

As shown in Fig. 2, for the two campaigns, the STC radar was very close to the Rhône-valley exit, whereas the other one, AIX or TLN, was installed more in the lee of the French Alps in northerly flow situations.

\section{Experimental results and discussions}

4.1 Horizontal-wind observations: a recall of previous results

Figure 3 shows STC a) and TLN b) UHF-profiler observations of the horizontal wind vector made during the 6-8 November 1999 (MAP). Maximum wind speeds of $35 \mathrm{~m} \mathrm{~s}^{-1}$ at $1300 \mathrm{~m}$, on 6 November, 21:00 UTC, and $30 \mathrm{~m} \mathrm{~s}^{-1}$ at $1100 \mathrm{~m}$, on 6 November, 19:00 UTC, are observed above STC and TLN, respectively. The Mistral wind direction is between NW and $\mathrm{N}$ during the whole episode, which is a classical feature.

The mechanisms responsible for the temporal evolution of the Mistral vertical structure have already been identified (Guénard et al., 2004). In summary, they are related to the evolution of the upstream synoptic wind speed and direction conditions during the event, i.e. from west to northwest, in the first part of the event, and north, in the second part, and the upstream Froude number, calculated in the layer below the upstream inversion height (measured by radiosounding at Lyon), as made by Pettré (1982). The Froude number has been found to be between 0.19 and 0.75 , thus systematically smaller than 1 (subcritical incident flow) during all the events. Therefore, the possibility for the air masses to pass over the mountains is mainly governed by the comparison between the upstream inversion height and the mountain elevations. In the case reported here, as the well-mixed depth becomes thinner and the flow accelerates along the Rhône-valley axis when the synoptic wind direction is north, the Mistral regime passes from a "deep" to a "shallow" type (such a transition is clearly visible in Figs. 3a and b). Then, the cessation of the Mistral at TLN, several hours before STC, is mainly due to the blocking of the low-level flow by 
(a) STC

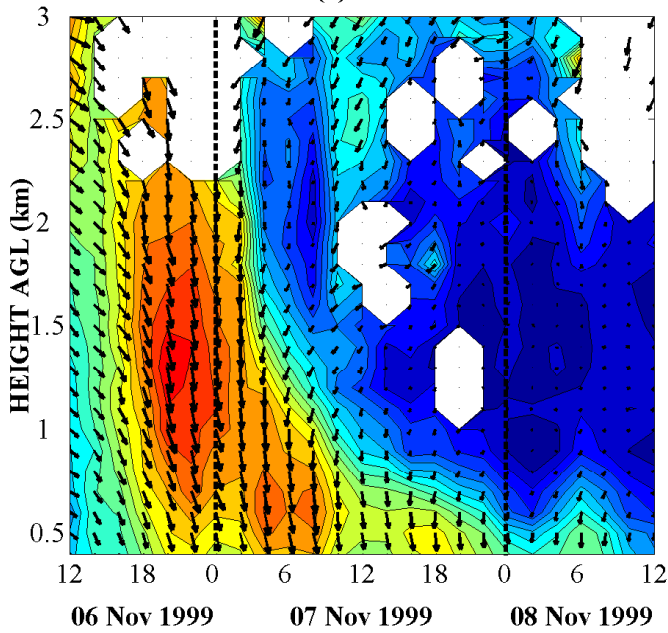

(c) STC

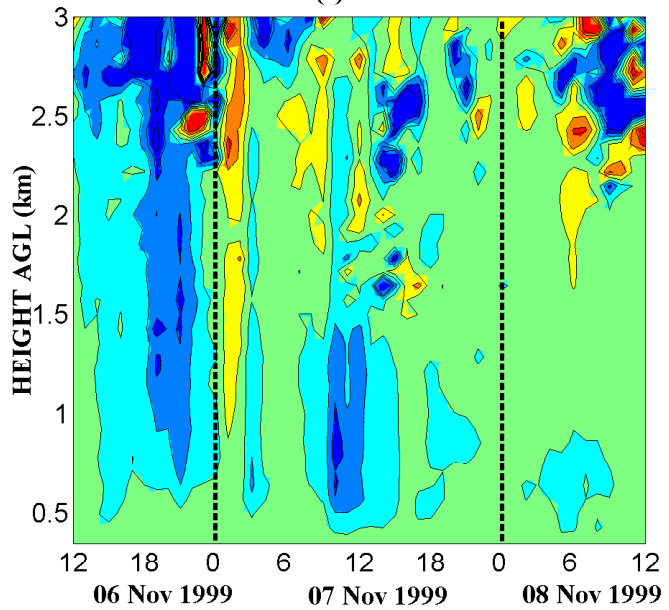

(e) STC

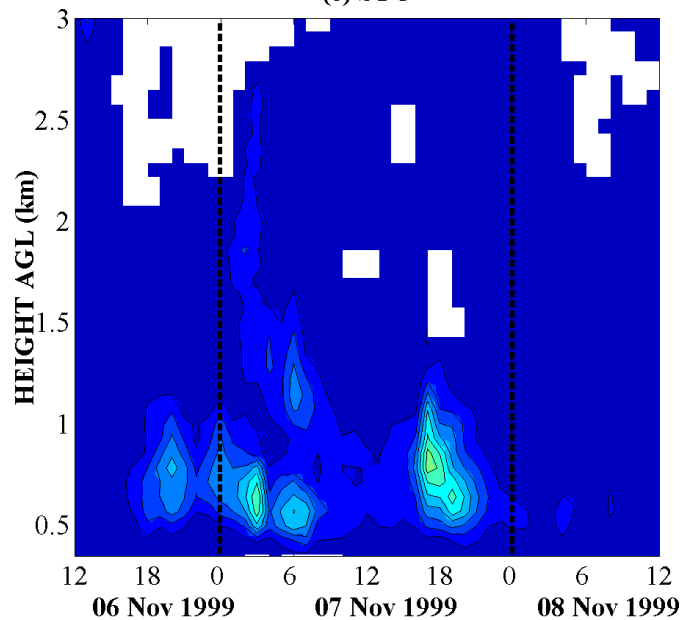

(b) TLN
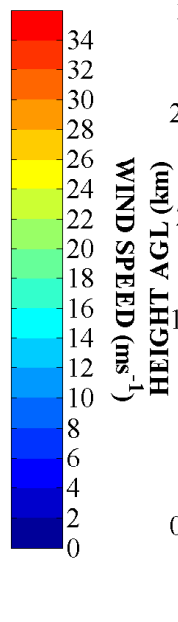

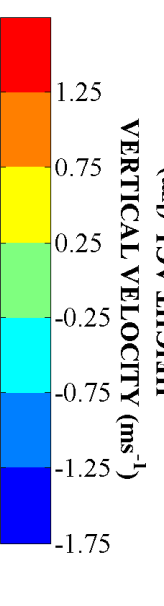

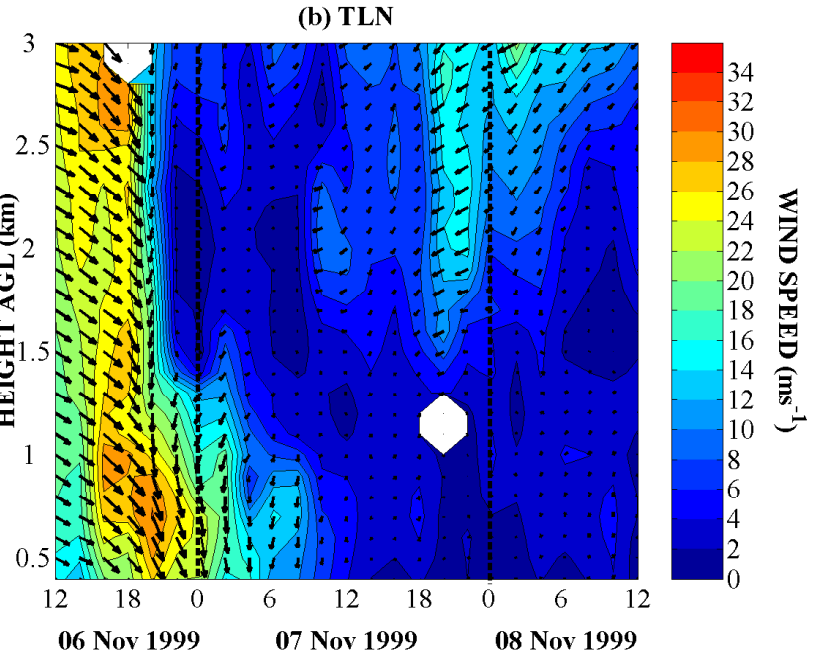

(d) TLN
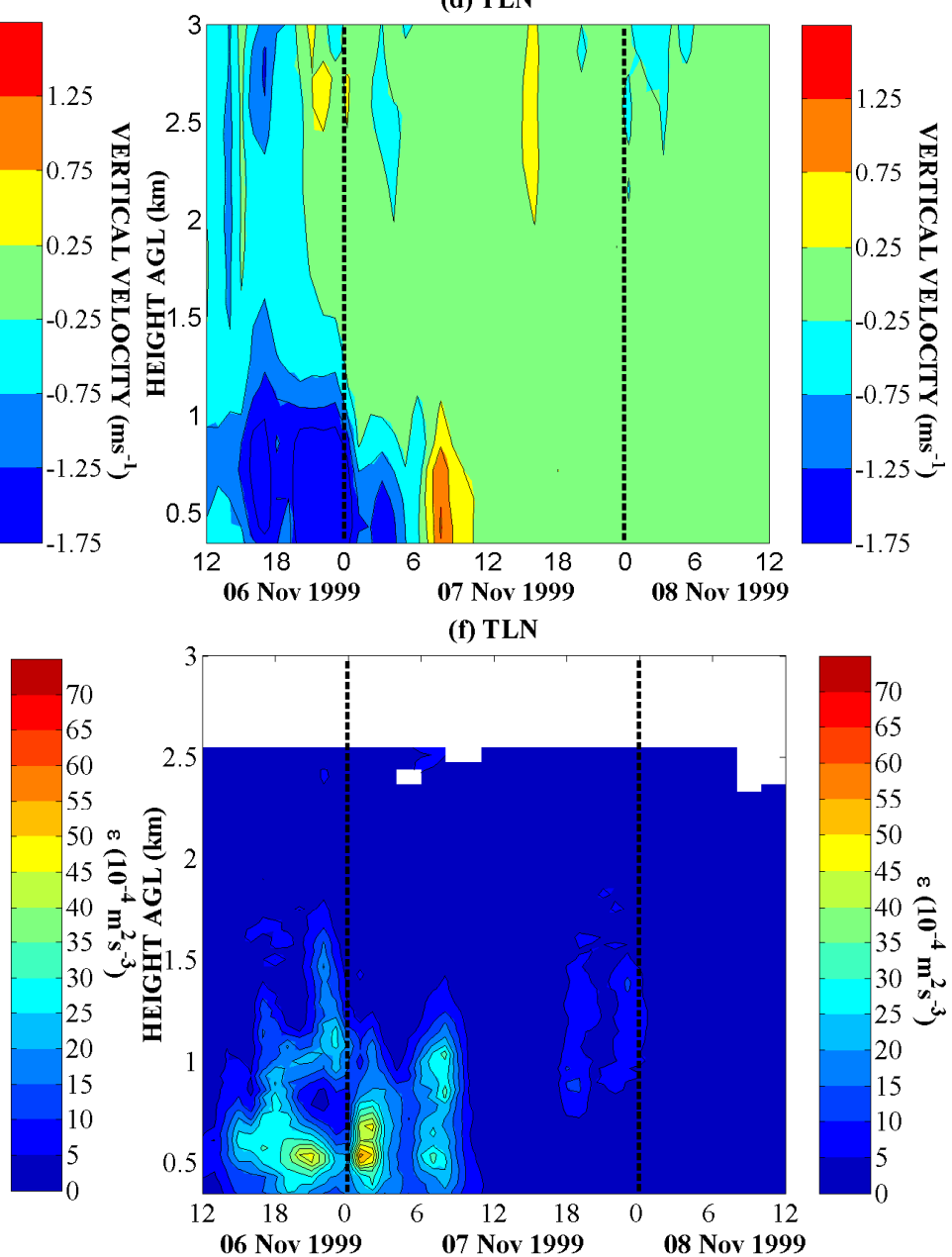

(f) TLN

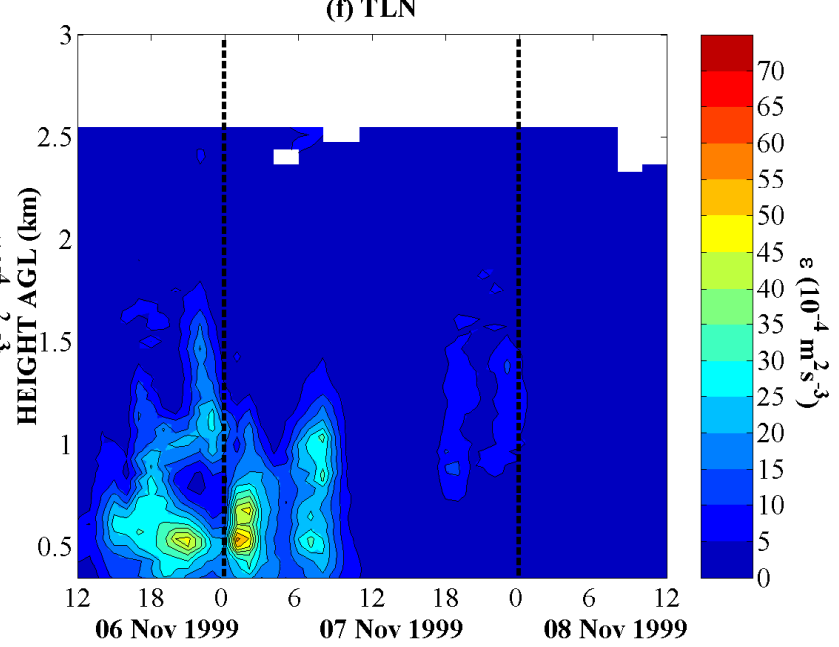

Fig. 3. Time-height diagrams of UHF-radar data obtained during the 6-8 November 1999 Mistral event (from the MAP Special Observing Period) above STC (a, c, e) and TLN (b, d, f). The vertical dotted lines indicate 00:00 UTC. (a) and (b): horizontal wind-vectors. The wind speed values are shown using a color code, whereas the wind directions are indicated by the superimposed arrows (a northerly wind corresponds to an arrow toward the bottom). The arrow lengths are proportional to the speed values. (c) and (d): vertical velocity values. (e) and (f): turbulent dissipation rate values. 
the Alps to the north of TLN (maximum upstream elevation around $3000 \mathrm{~m}$ ), whereas STC still observed air masses directly exiting from the Rhône valley. This result illustrates the important role played by the upstream orography to determine whether or not a given site is under the influence of the Mistral.

Figure 4 shows STC a) and AIX b) UHF-profiler observations of the horizontal wind vector made during the 21-23 June 2001 period (ESCOMPTE). The maximum wind speed values are between 12 and $15 \mathrm{~m} \mathrm{~s}^{-1}$ below $1500 \mathrm{~m}$.

This case is a Mistral event often observed in summer and featured by WNW synoptic upstream conditions (quasistationary during the whole event), weaker wind speeds and interactions with thermal circulations. Figures $4 \mathrm{a}$ and $\mathrm{b}$ clearly show that the Mistral blows at lower levels during the nights and is "lifted up" during the daytime, especially the afternoons where the ground heating is maximum and where the near-surface wind is weak (maximum of $5 \mathrm{~m} \mathrm{~s}^{-1}$ and the direction is more eastward. Those results are consistent with the presence of sea-breeze circulations.

For the 30 June-1 July 2001 event (see Fig. 5), which is a moderate Mistral case, the wind starts blowing on 30 June in the afternoon, with a maximum wind speed ranging from 15 to $18 \mathrm{~m} \mathrm{~s}^{-1}$ in the $1.5-2.5 \mathrm{~km}$ height slice above the two sites. During the onset phase and similarly to the 21-23 June event, weak westerly winds, i.e. between 2 and $10 \mathrm{~m} \mathrm{~s}^{-1}$, blow up to $1 \mathrm{~km}$ height. Although the time-height wind direction fields are quite similar above STC (Fig. 5a) and AIX (Fig. 5b), the time-height wind speed fields differ from one site to the other, despite their proximity (here $25 \mathrm{~km}$ apart). In particular, on 1 July, at AIX, the Mistral temporarily stops blowing between 00:00 UTC and 06:00 UTC, and the Mistral breakdown occurs at 12:00 UTC while it persists $12 \mathrm{~h}$ more at STC. This is possibly due to a slight shift in the upperlevel wind direction which may displace the Mistral eastern shear line above AIX while STC remains in the core of the Mistral (similarly to the 28 June 2001 case, see Drobinski et al., 2003). It should also be noticed that the "lift up" and the near-surface weak westerly wind are not observed during the afternoon on 1 July, probably because the Mistral wind is stronger than in the weak Mistral cases usually observed in summer.

The upstream Froude number is found between 0.05 and 0.46 , thus smaller than 1 , as for the autumn case, during both the summer cases. On the other hand, the wind speed values are significantly weaker and the upstream inversion height is less well marked and/or higher than in the autumn case. These are the main reasons why, in addition to the orographic effects, the thermal forcings can also strongly influence the wind vertical structure variations observed during the summer Mistral events.

In summary, the dynamics of the Mistral is highly dependent on the season because of the occurrence of specific synoptic patterns and because, during summer, thermal forcing leads to a combination of sea breeze with Mistral and weaker winds due to enhanced friction (see Fig. 4) while during autumn the absence of thermal turbulence leads to substancial acceleration as low-level jets are generated in stably stratified ABL. Also, the structure of the Mistral evolves rapidly and its dynamics differ from one location to another. At the exit of the Rhône valley, the gap flow dynamics dominates (see STC observations, Figs. 3a and 5a), whereas at the lee of the Alps the dynamics is driven by the relative contribution of "flow around" and "flow over" mechanisms upstream of the Alps (see TLN observations, Fig. 3b and AIX observations, Fig. 5b), themselves governed by the upstream Froude number conditions.

\subsection{Analysis of the vertical velocity and turbulent dissipation-rate fields}

Time-height vertical velocity and turbulent dissipation-rate fields in Mistral situations are presented here for the first time. The vertical velocity values have been temporally smoothed using a 2-h width moving-averaging window in order to remove short period waves.

The vertical velocity field observed on 6-8 November 1999 above STC and TLN and shown on Figs. 3c and d, respectively, reveals that the air masses are globally subsident during the Mistral activity. This behaviour is consistent with cold and dry air masses arriving from the north and observed above sites located beyond the last descending slopes before the sea. This is particularly true in November, where there is no significant ground heating and when the presence of lowlevel cold air makes the ABL statically stable. Figures 3c and d clearly show such a behaviour that represents quasisystematic negative vertical velocities in the height-time region concerned by the Mistral episode, with stronger values varying between -1 and $-1.5 \mathrm{~m} \mathrm{~s}^{-1}$ above STC and between -1.5 and $-2 \mathrm{~m} \mathrm{~s}^{-1}$ above TLN. These negative $\mathrm{w}$ values are strong and cannot be confused with the negative vertical bias of the order of $-10 \mathrm{~cm} \mathrm{~s}^{-1}$ that affects UHF vertical velocity measurements (Angevine, 1997).

Two patterns of relatively strong positive $w$ values are nevertheless observed, first, at STC around 01:00 UTC above $1 \mathrm{~km}$ of altitude (see Fig. 3c), and second, at TLN between 08:00 and 11:00 UTC below $1 \mathrm{~km}$ of altitude (Fig. 3d). In the first case, the positive $\mathrm{w}$ values are obtained in the Mistral core (see Fig. 3 a) but during a very short period $(\cong 1 \mathrm{~h}$ ) and cannot be explained by the pure Mistral dynamics. In the second case, the positive $\mathrm{w}$ values are observed during the Mistral erosion phase (Fig. 3b), that is when the wind speed progressively weakens, here from 12 to $4 \mathrm{~m} \mathrm{~s}^{-1}$ while keeping the same north direction. During this phase, a progressive and relative warming may occur which could temporarily lead to convective upward motions.

The turbulent dissipation-rate $(\varepsilon)$ fields obtained during this period with the same radars are consistent with a nonconvective situation free from ground heating, which is a common feature in autumn in a dry wind regime. Indeed, Figs. $3 \mathrm{e}$ and $\mathrm{f}$ show significant $\varepsilon$-values in the height-time regions where the wind shear (i.e. the square modulus of the vertical derivative of the horizontal wind) is strong (see Figs. 3a and b), independent of nighttime or daytime peri- 
(a) $\mathrm{STC}$

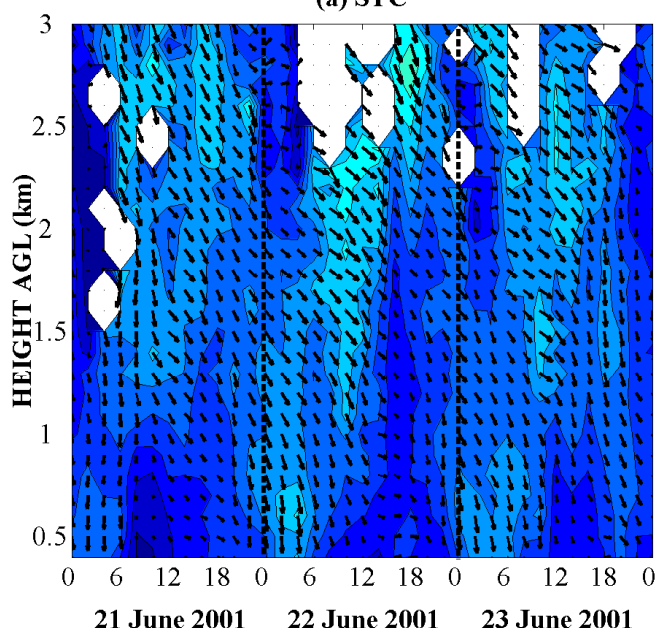

(c) STC

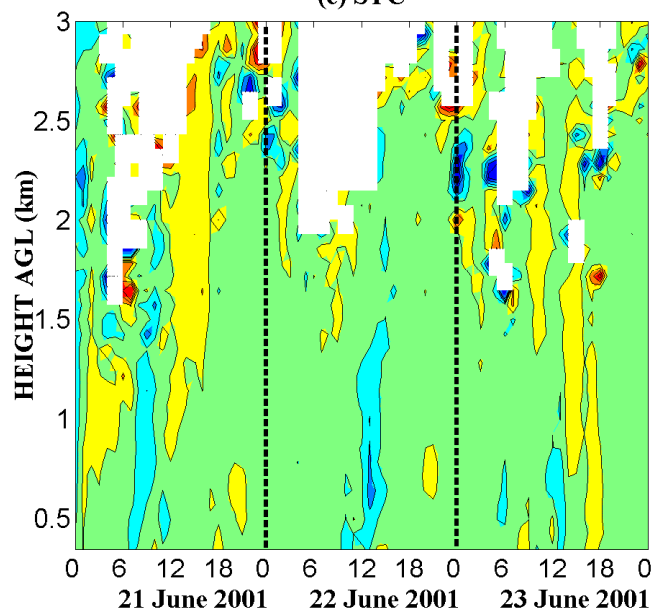

(e) STC

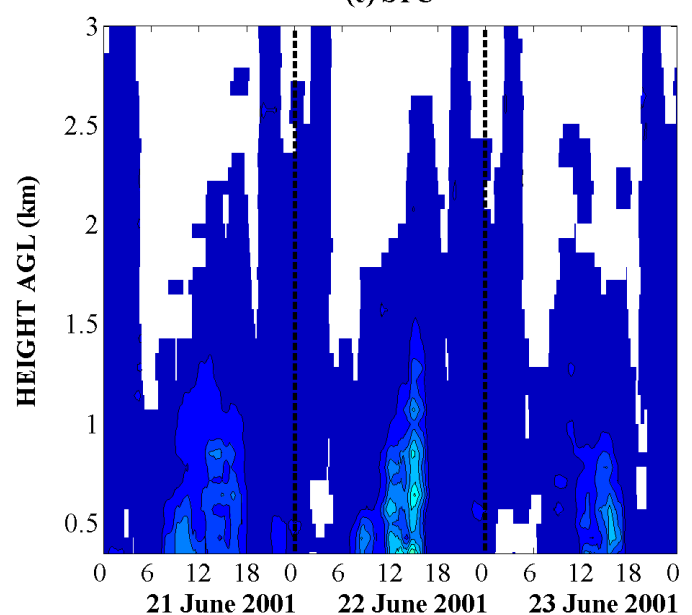

(b) AIX
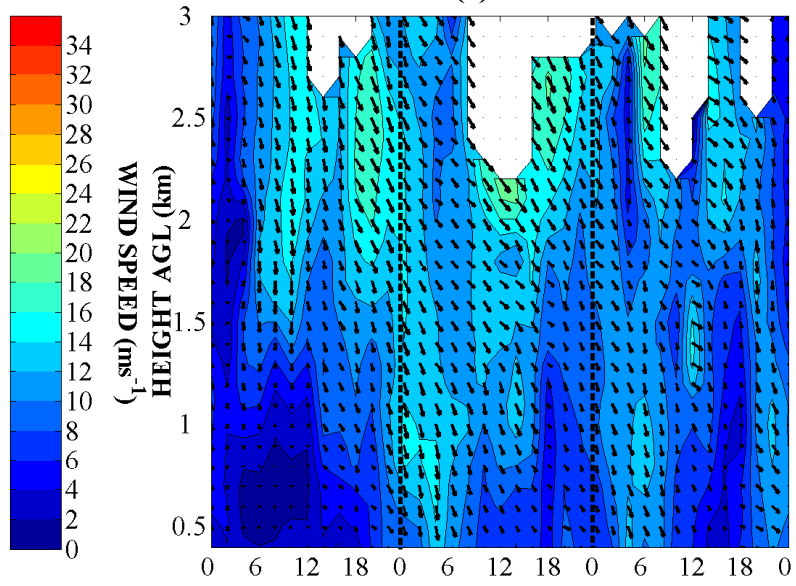

21 June 200122 June 200123 June 2001

(d) AIX
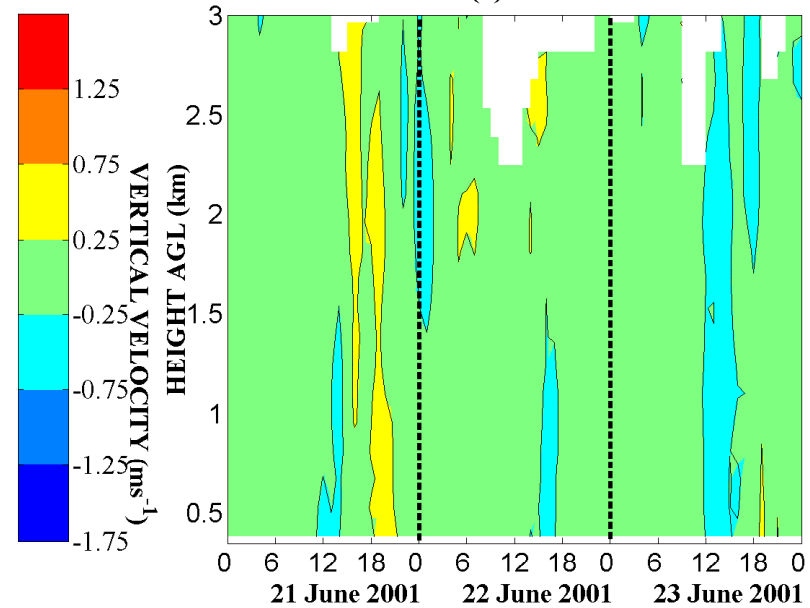

(f) AIX

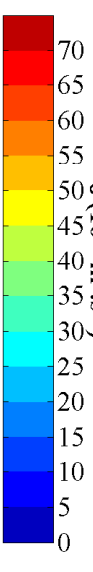

70
65
60
-55
$-50 \mathrm{~m}$
$-45 \Xi$
-40
-35
-30
-25
-20
15
10
5
0

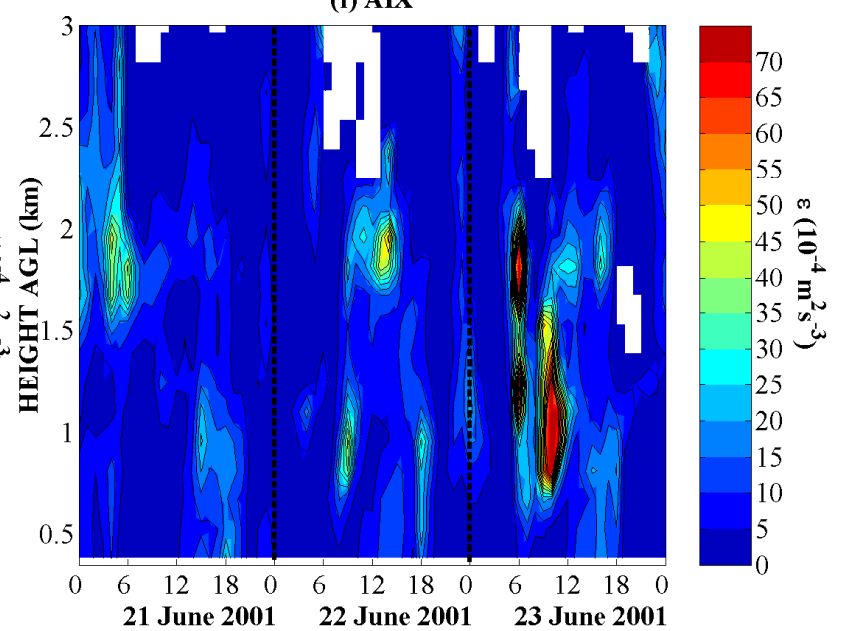

Fig. 4. Same as Fig. 3, at STC (a, c, e) and AIX (b, d, f), during the 21-23 June 2001 Mistral event (from the ESCOMPTE Special Observing Period).

ods. Detailed comparisons between Figs. 3e and a, for the STC case, and between Figs. 3f and b, for the TLN case, show that the enhanced $\varepsilon$ values are obtained in time-height areas corresponding to sharp variations of wind speed with altitude. Indeed, the wind shear calculated in these areas ranges from 20 to $38 \mathrm{~m} \mathrm{~s}^{-1} / \mathrm{km}$. Such particularly high values suggest that the turbulence is purely of dynamical origin, probably generated by strong wind shears associated with a 
(a) STC

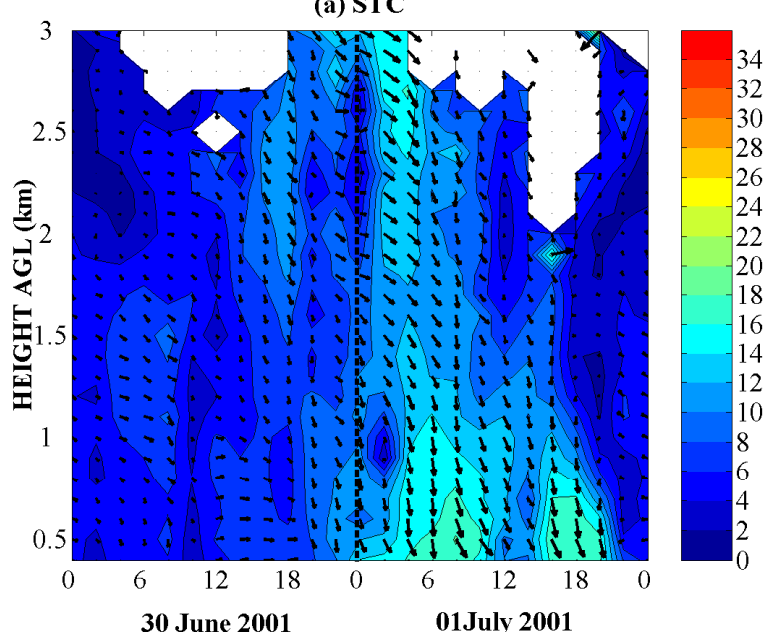

(c) STC

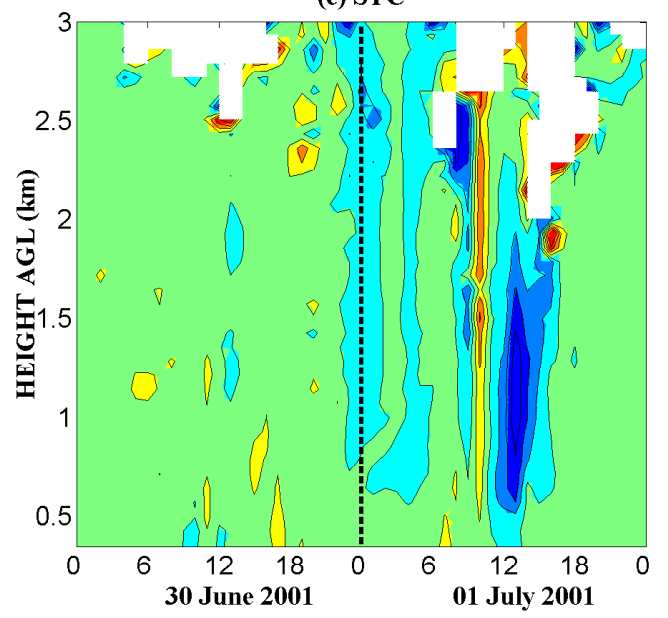

(e) STC

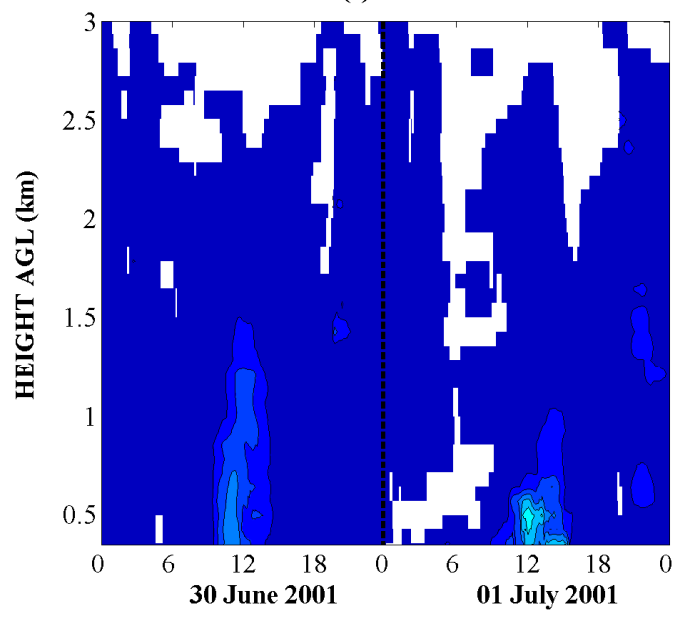

(b) AIX

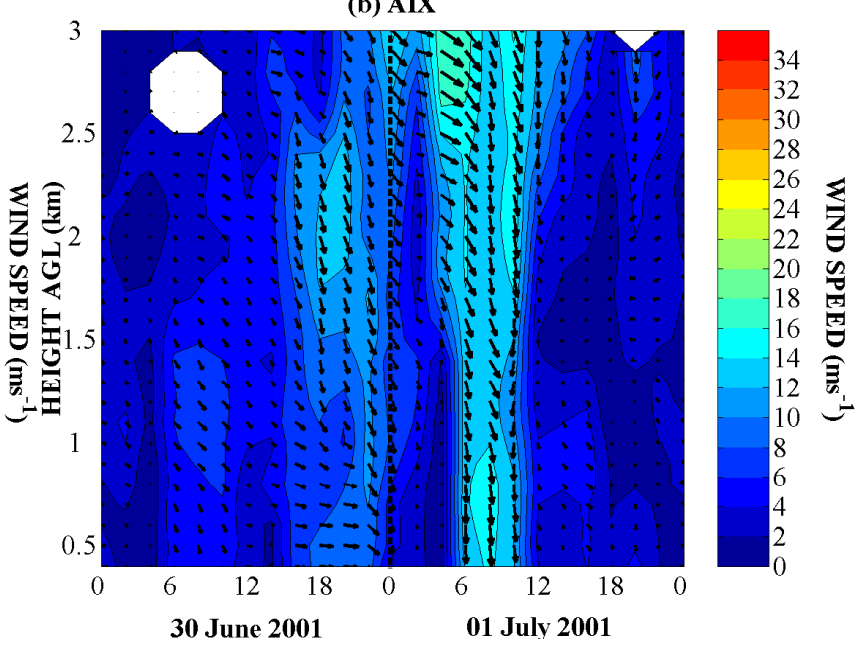

(d) AIX
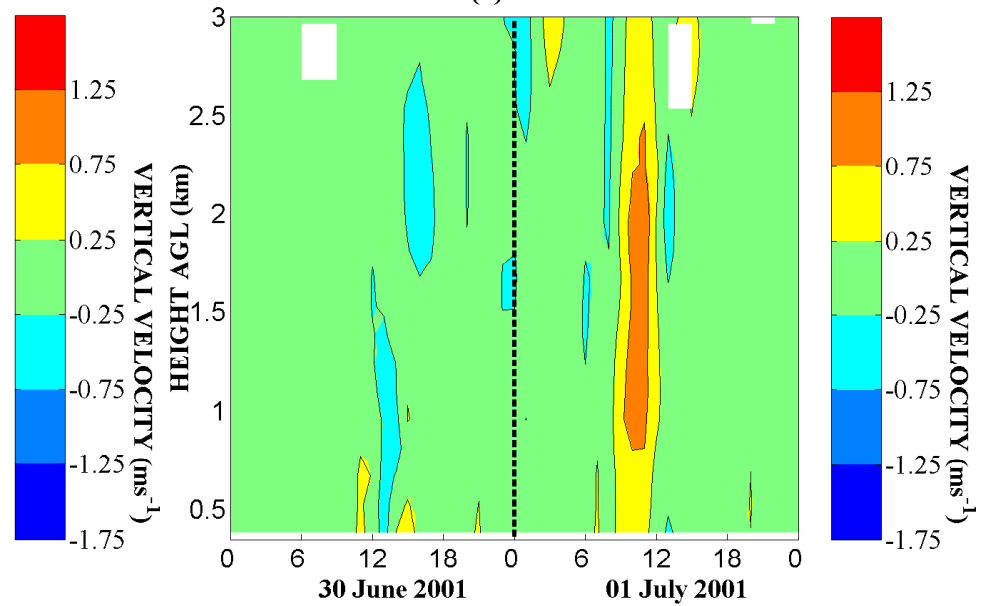

(f) AIX

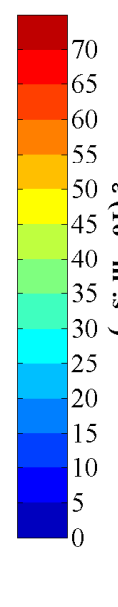

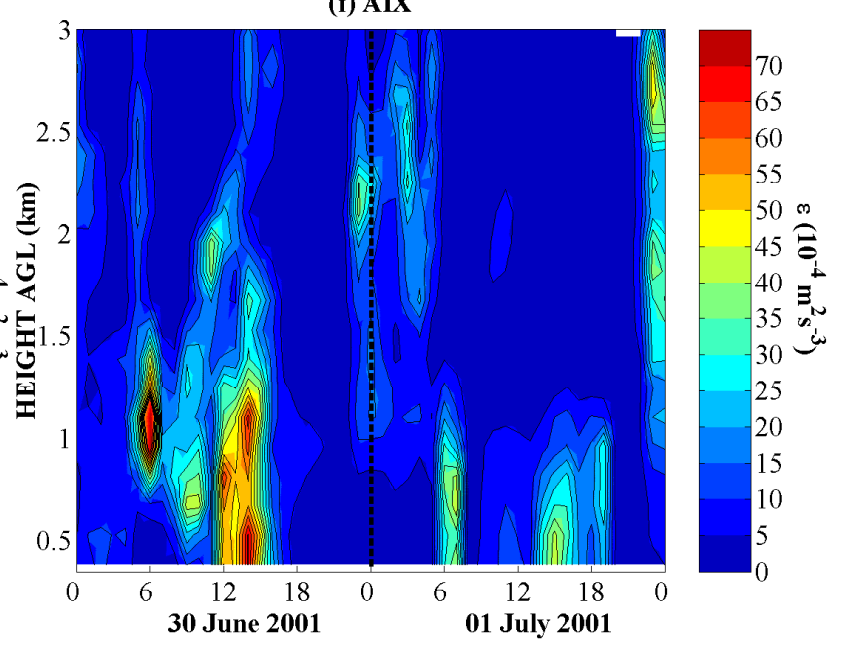

Fig. 5. Same as Fig. 3, at STC (a, c, e) and AIX (b, d, f), during the 30 June-1 July Mistral event (from the ESCOMPTE Special Observing Period).

high static stability. More explicitly, such a turbulence generated in stably stratified flow is due to dynamic instabilities induced by wind shears. This is observed when and where the vertical shear of the horizontal wind is strong enough to make the gradient Richardson number, i.e. the static stability to wind shear ratio, positive but smaller than 0.2 (e.g. Tennekes and Lumley, 1972). Though less significant, enhanced $\varepsilon$-values are also obtained above TLN (Fig. 3f), be- 
tween 800 and $1600 \mathrm{~m}$ and between 7 November, 18:00 UTC and 8 November, 01:00 UTC, that is within the period where the lower-level air masses are blocked upstream by the Alps (see previous sub-section). This is probably the signature of the mountain/lee waves breaking, as suggested by Jiang et al. (2003), which mainly occur in the lee of the lateral sides of the Rhône valley, here the eastern side. As a possible confirmation, it should be noticed that those enhanced $\varepsilon$ values are obtained in a quasi-absence of wind (around $3 \mathrm{~m} \mathrm{~s}^{-1}$ in average, see Fig. 3b), which suggests that the main origin of the turbulence is not simply wind shear, as in the previous case. Turbulence induced by breaking mountain waves has been simulated by Fritts et al. (1994) and observed by Ralph et al. (1997). In those papers the complexity of the relationship beween shear-induced and/or convective origins for the turbulence production during a mountain wave breaking episode is underlined.

The vertical velocity fields obtained during summer Mistral events are presented in Figs. 4c and 5c, for STC, and Figs. 4d and 5d, for AIX. As expected, clear signatures of global subsidence during Mistral episodes are no longer visible in those cases where ground heating and thermal circulations perturb the ABL dynamics. It is nevertheless noticeable that the vertical velocity scale below $1500 \mathrm{~m}$ is -0.75 to $0.75 \mathrm{~m} \mathrm{~s}^{-1}$ during daytimes, i.e. from $06: 00$ to 21:00 UTC, whereas they are between -0.25 and $0.25 \mathrm{~m} \mathrm{~s}^{-1}$ during night-times, i.e. from 21:00 to 06:00 UTC. These observations are consistent with a less convective, or more stabilized ABL, during nighttimes, due to the night ground cooling, which tends to prevent vertical motions. During daytimes, convective vertical motions are possible which explain stronger vertical velocity values.

Time-height diagrams of $\varepsilon$ obtained during the summer weak Mistral event are shown in Fig. 4e, for STC, and Fig. 4f, for AIX. These figures show enhanced $\varepsilon$ values for the same periods where the Mistral is "lifted up" (see previous subsection and Figs. 4a and b, that is during daytimes and especially during the afternoons where the ground heating is maximum. This is consistent with the installation of diurnal convective boundary layers characterized by the development of convective turbulence (Heo et al., 2003). The same behaviour is observed in the afternoon of 30 June 2001 (see the left part of Figs. 5e and $\mathrm{f}$ where the Mistral is still weak. On the other hand, on 1 July 2001, at STC, the time-height region of enhanced $\varepsilon$ values is only visible around 12:00 UTC (see the right part of Fig. 5e, that is precisely in the period during which the Mistral wind temporarily weakens (see the right part of Fig. 5a, while the "lift up" and the eastward nearsurface direction shift are not observed. This suggests that, in summer, a relatively strong Mistral case (a moderate case if compared to mid-season and winter cases) can perturbed the installation of both convective turbulence and sea-breeze circulation.

For the two summer cases, significantly higher $\varepsilon$ values are observed above AIX (Figs. 4f and 5f) than above STC (Figs. 4e and 5e). This could be explained by the proximity of the sea (the Berre pond, see Fig. 1), in the STC case, which makes the surface temperature cooler than in the AIX case where the radar is installed $20 \mathrm{~km}$ inland.

It should be noticed that $\varepsilon$ maximum values around 30 $10^{-4} \mathrm{~m}^{2} \mathrm{~s}^{-3}$ and $7010^{-4} \mathrm{~m}^{2} \mathrm{~s}^{-3}$ are found for the summer cases at STC (Figs. 4e and 5e) and AIX (Figs. 4f and 5f), respectively. Those maximum values are consistent with those, within the $30-4010^{-4} \mathrm{~m}^{2} \mathrm{~s}^{-3}$ range, obtained by JacobyKoaly et al. (2002), using UHF profiler and in-situ aircraft data, for typical summer anticyclonic situations (no wind cases) and above a very large and flat terrain (the Beauce plain in central France).

The $\varepsilon$ maximum values between $4010^{-4}$ and $5010^{-4} \mathrm{~m}^{2}$ $\mathrm{s}^{-3}$ found for the autumn case (Figs. 3e and f) proves that the intensity of the turbulence dynamically produced may be of the same order of magnitude as the one produced by convection. Finally, during the summer nights and as for the autumn case, significant dynamically-induced $\varepsilon$ values could be expected when the Mistral recovers its low-level jet structure. Here, such high $\varepsilon$ values are not obtained probably because the wind shears are not strong enough. Indeed, wind shear values between 8 and $18 \mathrm{~m} \mathrm{~s}^{-1} / \mathrm{km}$ are found instead of the 20 to $38 \mathrm{~ms}^{-1} / \mathrm{km}$ previously mentioned.

\section{Summary and concluding remarks}

Some mesoscale and seasonal aspects of the Mistral in coastal area have been investigated thanks to UHF profiler data. In addition to the already analysed classical horizontal wind values, vertical velocity and turbulent parameter (the turbulent dissipation rate $\varepsilon$ ) values are presented and interpreted here for the first time in Mistral situations.

In autumn, when the ground is cool, the Mistral has a synoptically and orographically forced low-level jet structure. The wind speed can be strong, the depth strongly depends on the upstream conditions and on the observation sites (wind fields observed above two places $90 \mathrm{~km}$ apart may be very different) and the air masses are globally subsident when they approach the sea, as expected from a cold and dry wind regime in a stable ABL. In these non-convective cases the turbulence is of pure dynamic origin and can be due to the permanent wind shears or, in some occasion, to mountain/lee wave breaking which can occur over the lateral mountainous sides of the Rhône valley.

In summer, the Mistral winds are weaker and diurnal variations are observed. During daytimes, the installation of a convective boundary layer, revealed by enhanced $\varepsilon$-values, and the sea-breeze circulations tend to weaken and "lift up" the Mistral in weak cases. Such convective boundary layer and sea-breeze circulation installations are perturbed when the Mistral is stronger. In any case, our results suggest that the thermal effects are the main factor for the turbulence development and that such convective turbulence has the same intensity as the dynamical turbulence observed in the autumn case. Our results also show that during the convective turbulence episodes the vertical motions are much more developed than during nighttimes where the $\mathrm{ABL}$ is cooler, thus more 
stabilized. During nighttimes, because of the ground cooling, the Mistral recovers its low-level jet structure.

In addition to the above mentioned low-tropospheric/ABL physics, our results show that the vertical velocity at lower levels and the turbulent dissipation rate can be reliably measured and estimated from UHF wind profilers. Indeed, our experimental values are consistent with both our Mistral basic knowledge and the already analysed horizontal wind measurements. Future works will consist of further developments in the technique of turbulent dissipation rate estimation by UHF profiler in dynamically perturbed situations and of comparisons of such a radar-derived parameter with mesoscale model simulations.

Acknowledgements. The CNRS, the INSU/PATOM, the INSU/PNCA, Météo-France, Ets. Degréane, and EDF are gratefully acknowledged for their financial and/or logistical supports. The authors are also thankful for the efforts made by the number of international committees, working groups and staffs during the MAP and ESCOMPTE Special Observing Periods.

Topical Editor O. Boucher thanks M. Teshiba and another referee for their help in evaluating this paper.

\section{References}

Angevine, W. M.: Errors in mean vertical velocities measured by boundary layer wind profilers, J. Atmos. Oceanic Technol., 14, 565-569, 1997.

Blondin, C. and Bret, B.: Numerical study of the Mistral with a mesoscale model. Scientific results of the Alpine experiment (ALPEX), GARP Publication Series, WMO/TD, 549-563, 1986.

Bougeault, P., Binder, P., Buzzi, A., Dirks, R., Houze, R., Kuettner, J., Smith, R. B., Steinacker, R., and Volkert, H.: The MAP Special Observing Period, Bull. Amer. Meteor. Soc., 82, 433-462, 2001.

Caccia, J.-L., Aubagnac, J.-P., Béthenod, G., Bourdier, C., Bruzzese, E., Campistron, B., Candusso, J.-P., Chérel, G., Claeyman, J.-P., Conrad, J.-L., Cordesses, R., Currier, P., Derrien, S., Despaux, G., Dole, J., Durbe, R., Fournet-Fayard, J., Frappier, A., Ghio, F., Girard-Ardhuin, F., Jacoby-Koaly, S., Klaus, V., Ney, R., Pagès, J.-P., Petitdidier, M., Pointin, Y., Richard, E., Seloyan, I., Smaïni L., and Wilson, R.: The French ST-radar network during MAP: observational and scientific aspects, Meteor. Zeit., 10, 469-478, 2001.

Corsmeier, U., Behrent, R., Drobinski, P., and Kottmeier, C.: The Mistral and its effect on air pollution transport and vertical mixing, Atmos. Res., in press, 2004.

Cros, B., Durand, P., Cachier, H., Drobinski, P., Fréjafon, E., Kottmeier, C., Perros, P. E., Peuch, V. H., Ponche, J. L., Robin, D., Saï, F., Toupance, G., and Wortham, H.: The ESCOMPTE Program: An overview, Atmos. Res., 69, 241-279, 2004.

Drobinski, P., Guénard, V., Dabas, A. M., Bastin, S., Caccia, JL., Campistron, B., Delville, P., Reitebuch, O., and Werner, C.: Combined observations by airborne Doppler lidar and UHFwind profilers of the 28 June 2001 Mistral event during the ESCOMPTE field experiment, 6th Int. Symp. on Tropospheric Profiling : needs and technologies, Leipzig, Germany, 2003.

Druilhet, A., Benech, B., Caccia, J-L., Richard, E., Campistron, B., Flamant, C., Lothon, M., Saïd, F., Caminade, C., and Guénard, V.: Experimental and numerical analysis of a Mistral case dur- ing MAP experiment in relation with the PV banner observation, 10th AMS Conf. on Mountain Meteorology, Park City, Utah, USA, 2002.

Ecklund, W. L., Carter, D. A., and Balsley, B. B.: A UHF wind profiler for the boundary layer: brief description and initial results, J. Atmos. Oceanic Technol., 5, 432-441,1988.

Fritts, D. C., Andreassen, J. R., and Isler, J. R.: Gravity wave breaking in two and three dimensions 2 . Three-dimensional evolution and instability structure, J. Geophys. Res., 99, 8109-8123, 1994.

Gage, K. S., Williams, C. R., and Ecklund, W. L.: UHF wind profiler: A new tool for diagnosing tropical convective clouds systems, Bull. Am. Meteorol. Soc., 75, 2289-2294, 1994.

Guénard, V., Caccia, J-L., Campistron, B., and Drobinski, P.: UHFradar investigations of low-tropospheric mesoscale dynamical processes, 2nd European Conf. on Radar Meteorology, Delft, The Netherlands, 428-432, 2002.

Guénard, V., Drobinski, P., Caccia, J-L., Campistron, B., and Bénech, B.: An observational study of the Mistral mesoscale dynamics, Bound.-Layer Meteor., accepted, 2004.

Heo, B. H., Jacoby-Koaly, S., Kiung-Eak, K., Campistron, B., Bénech, B., and Eun-Sil, J.: Use of the Doppler spectral width to improve the estimation of the convective boundary layer height from UHF wind profiler observations, J. Atmos. Oceanic Technol., 20, 408-424, 2003.

Jacoby-Koaly, S., Campistron, B., Bernard, S., Bénech, B., Ardhuin-Girard, F., Dessens, J., Dupont, E., and Carissimo, B.: Turbulent dissipation rate in the boundary layer via UHF wind profiler Doppler spectral width measurements, Bound.-Layer Meteor., 103, 361-389, 2002.

Jiang, Q., Smith, R. B., and Doyle, J. D.: The nature of the Mistral: observations and modelling of two MAP events, Quart. J. Roy. Meteor. Soc., 129, 857-876, 2003.

Lafore, J.-P., Stein, J., Ascensio, N., Bougeault, P., Ducrocq, V., Duron, J., Fisher, C., Héreil, C., Mascart, P., Pinty, J.-P., Richard, E., and Vila-Guerau, J.: The Meso-NH atmospheric simulation system. Part I: Adiabatic formulation and control simulations, Ann. Geophys., 16, 90-109, 1998.

Lothon, M., Campistron, B., Jacoby-Koaly, S., Bénech, B., Lohou, F., Girard-Ardhuin, F., and Druilhet, A.: Comparison of radar reflectivity and vertical velocity observed with a scannable C-band Doppler radar and two UHF profilers in the lower troposphere, J. Atmos. Oceanic Technol., 19, 899-910, 2002.

Lothon, M., Campistron, B., Jacoby-Koaly, S., Bénech, B., Lohou, F., Girard-Ardhuin, F., and Druilhet, A.: Reply to the comment on 'Comparison of radar reflectivity and vertical velocity observed with a scannable C-band Doppler radar and two UHF profilers in the lower troposphere', J. Atmos. Oceanic Technol., 20, 1224-1229, 2003.

Pettré, P.: On the problem of violent valley wind, J. Atmos. Sci., 39, 542-554, 1982.

Ralph, F. M., Neiman, P. J., and Levinson, D.: Lidar observations of a breaking mountain wave associated with extreme turbulence, Geophys. Res. Let., 24, 663-666, 1997.

Tafferner, A. and Egger, J.: Test of theories of lee cyclogenesis: ALPEX cases, J. Atmos. Sci., 47, 2417-2428, 1990.

Tennekes, H. and Lumley, J. L.: A first course in turbulence, M.I.T. press, 300, 1972.

Trigo, I. F., Davies, T. D., and Big, G. R.: Objective climatology of cyclones in the Mediterranean region, J. Climate, 12, 1685-1696, 1999. 